\title{
Performances indígenas y afrodescendientes en Argentina: recreaciones sonoro-corporales de lo "ancestral"
}

\author{
Indigenous and afrodescendant performances in Argentina: \\ sound-corporal recreations of the "ancestral"
}

\author{
Silvia Citro* \\ Universidad de Buenos Aires / Conicet \\ Manuela Rodríguez ${ }^{* * *}$ \\ Universidad Nacional de Rosario / Conicet
}

\author{
Julia Broguet ${ }^{* *}$ \\ Universidad Nacional de Rosario / Conicet \\ Soledad Torres Agüero ${ }^{* * * *}$ \\ Universidad de Buenos Aires
}

DOI: $10.22380 / 2539472 X .1090$

\section{RESUMEN}

A partir de las políticas públicas del Estado argentino en relación con las poblaciones indígenas y afrodescendientes, examinamos de qué manera las políticas culturales de las provincias de Formosa y Santa Fe, especialmente entre 2003 y 2015, tendieron a visibilizar y revalorizar las performances "ancestrales" de estos pueblos. Analizaremos cómo, frente a las interpelaciones multiculturales por performativizar las identidades étnico-raciales ante la sociedad hegemónica, los/as performers fueron estimulados/as a seleccionar, recrear y espectacularizar determinadas sonoridades, movimientos e imágenes inscritas tanto en repertorios corporizados como en archivos. También exploramos cómo en estos procesos de recreación sonoro-corporal de las memorias se construyen nuevos archivos, con la intención político-cultural de resguardar y legitimar una determinada versión de las posiciones identitarias étnico-raciales puestas en juego.

\begin{abstract}
Based on public policies of the Argentine State in relation to indigenous and Afro-descendant people we examine how the cultural policies of the provinces of Formosa and Santa Fe, especially during 2003-2015, tended to make visible and enhance the "ancient" performances of these groups. We will analyze how to face the multicultural interpellations of performing ethnic-racial identities before the hegemonic society, the performers were encouraged to select, recreate, and spectacularize certain sounds, movements and images to be found both in embodied repertoires and in archives. We also explore how in these sound and corporal recreation processes of memories new archives are created with the political-cultural intention to safeguard and legitimate certain versions of the ethnic-racial identity positions.
\end{abstract}

Keywords: multiculturalism, performances, ethnic-racial identities, cultural policies.

Palabras clave: multiculturalismo, performances, identidades étnico-raciales, políticas culturales.

\footnotetext{
scitro_ar@yahoo.com.ar / https://orcid.org/0000-0002-4597-3733

juliabroguet@gmail.com / https://orcid.org/0000-0001-8246-1203

... manuela.guez@gmail.com / https://orcid.org/0000-0002-0761-0763

...._soledadta@gmail.com / https://orcid.org/0000-0003-4365-1113
} 


\section{Introducción ${ }^{1}$}

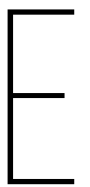

specialmente desde los años noventa, las políticas globales que promueven ideologías multiculturalistas y procesos de patrimonialización han influenciado las políticas culturales de los Estados nación latinoamericanos y han promovido las performances de diferentes grupos socioculturales, así como la redefinición de sus posicionamientos étnico-raciales. En este proceso, fue clave la Convención para la Salvaguardia del Patrimonio Cultural Inmaterial, promulgada en 2003 por la Unesco, y en el caso argentino, la Ley 26118, sancionada en 2006 por el Estado nacional, que ratificó esta Convención y adhirió a todos sus artículos. En este marco, algunas de las provincias con población indígena o afrodescendiente, que hasta ese entonces habían invisibilizado o incluso negado a estos grupos y sus expresiones culturales, lentamente comenzaron a promocionarlos como parte de su patrimonio, a través de diferentes políticas culturales. Tal es el caso de las performances indígenas en la provincia de Formosa y las afrodescendientes en Santa Fe, que abordaremos en este artículo.

Diversos autores han analizado el modelo excluyente de nación que caracterizó el periodo de consolidación del Estado argentino —entre mediados del siglo XIX y principios del siglo XX-, en el que las élites intelectuales y políticas buscaron consolidar un paradigma eugenésico, racista, sexista y altamente homogeneizador que excluyó a indígenas y afrodescendientes (Briones 2005a; Segato 1999; Solomianski 2003; Terán 1987; entre otros). Este paradigma dio lugar a un proyecto nacional posindependentista que implicó el blanqueamiento de la población como el camino para "la civilización": un "crisol de razas" conformado fundamentalmente por segmentos blancos europeos. No obstante, como ha planteado Briones (2005a; 2005b), los Estados provinciales fueron "copiando con diferencia” esos lineamientos, de acuerdo con sus formaciones históricas específicas en torno al vínculo provincia/nación y provincia / alteridades internas.

Como hemos analizado en trabajos anteriores (Citro y Torres Agüero 2012; Citro, Mennelli y Torres Agüero 2017), el campo de las políticas culturales y patrimoniales está siendo ampliamente problematizado en las antropologías latinoamericanas (Bayardo 2008; Chaves, Montenegro y Zambrano 2010; Crespo, Losada y Martín 2007; Gonçalves 1996; Lacarrieu 2000; Ochoa 2003; Rotman 2004; entre otros), aunque en Argentina son pocos aún los estudios que se enfocan en su

1 Este trabajo es parte de los resultados de un proyecto de investigación comparativo titulado "Performances indígenas y afrodescendientes en las políticas culturales regionales" (UBACyT 20020120100014BA). 
implementación en provincias con población indígena (Citro y Torres Agüero 2012, 2015; Kropff 2004; Roig 1996; Ruiz y Citro 2002) o afrodescendiente (Annecchiarico 2018; Broguet, Picech y Rodríguez 2014; Parody 2015; Schávelzon 2003). Por consiguiente, en la primera parte del trabajo sintetizamos las políticas del Estado argentino con relación a indígenas y afrodescendientes, para comprender así comparativamente las políticas culturales de las provincias de Formosa y Santa Fe entre 2003 y 2015. Nuestra hipótesis general sostiene que, en este periodo, el diseño de las políticas culturales provinciales estuvo notoriamente influenciado por las políticas globales y nacionales en torno al multiculturalismo y la necesidad de patrimonialización de determinadas expresiones artístico-culturales, lo cual favoreció la revalorización de aquellas expresiones consideradas “ancestrales” de "pueblos originarios” y "afrodescendientes”; de este modo, se tendió a reproducir una noción esencialista de la cultura, mayormente anclada en el pasado, en desmedro de las problemáticas socioculturales actuales de estos grupos.

En la segunda y tercera parte nos centraremos en las políticas de promoción de las denominadas música toba o qom, en Formosa, y candombe litoraleño, vinculado a una organización de afrodescendientes de Santa Fe. Para ello, tomaremos especialmente la labor de dos performers mujeres que han sido fundamentales para sus respectivas divulgaciones: Ema Cuañeri y Lucía Molina. Nuestra hipótesis específica es que, frente a las interpelaciones multiculturales por performativizar las identidades étnico-raciales, estas y otros/as performers indígenas y afrodescendientes han sido estimuladas/os a seleccionar, recrear y espectacularizar determinadas sonoridades, movimientos e imágenes que consideran ancestrales, inscritos tanto en repertorios corporizados como en archivos performáticos. Asimismo, veremos de qué manera estos procesos de recreación sonoro-corporal de las memorias impulsan la generación de nuevos archivos que, como las producciones discográficas, resultan fundamentales para resguardar, transmitir y legitimar una determinada versión de las identidades étnicoraciales puestas en juego.

En nuestra investigación, partimos de asumir que la noción de patrimo$n \mathrm{o}^{2}$ es resultado de una construcción sociocultural históricamente situada, cuyo rasgo fundamental es "su capacidad para representar, mediante un sistema de símbolos, una determinada identidad” (Prats 1997, 1-2). Por tanto, entendido como recurso (Yúdice 2002), lo patrimonial solo existe en la medida en que es

2 Cabe aclarar que la discusión más extensa sobre la noción de patrimonio, así como el examen detallado de las políticas culturales en cada provincia, fue realizado en artículos anteriores de las autoras (Broguet, Picech y Rodríguez 2014; Citro, Mennelli y Torres 2017; Citro y Torres 2012, 2015). 
activado (Prats 1997) dentro de los complejos campos de las políticas culturales que articulan lo global, lo nacional y lo local. Así, toda activación patrimonial depende fundamentalmente de la pugna entre distintos poderes políticos y de la capacidad para generar un cierto consenso entre diferentes instituciones y agentes gubernamentales y de la sociedad civil sobre aquello que es patrimonializable y aquello que no; pugna que, además, produce "rendimientos que los diversos sectores se apropian de manera desigual” (García Canclini 1999, 43).

Para analizar estos procesos situados de activación patrimonial desde la perspectiva de los/as performers indígenas y afrodescendientes, nuestra aproximación teórico-metodológica ha venido articulando desarrollos de los estudios de la performance y de la performatividad. A partir de los trabajos de Schechner (2000), Taylor (2003) y Turner ([1985] 2002), retomamos la noción de performance cultural para caracterizar aquellas prácticas que combinan expresiones musicales, corporales, visuales y discursivas, y que, a la vez, son representativas y constitutivas de diversas identidades socioculturales. Consideramos que esta noción es la más adecuada para describir las prácticas estéticas indígenas y afrodescendientes que, a diferencia de aquellas propias de la modernidad eurooccidental, no escinden estas expresiones (Citro 2009). Tanto el candombe como otros géneros de lo que hoy se denomina música toba pueden abordarse en tanto expresiones performáticas que unen canto, danza y ejecución instrumental; por ello, también, utilizamos la expresión performers - y no solo cantante y/o bailarina-para referirnos a Ema y a Lucía.

Asimismo, como sostenemos en nuestra hipótesis, entendemos que en este proceso de producción de la cultura como recurso patrimonializable, la recreación y la espectacularización de determinadas expresiones identificadas como ancestrales resulta crucial para legitimar ciertas performances culturales como propias de una "identidad" étnico-racial. Por ello, a partir de la noción de Butler (1999), consideramos que se trata de un proceso de negociación performativo, pues a través de estas expresiones estéticas performáticas se retoman y reactualizan — reproduciendo pero también disputando- los imaginarios, comportamientos y saberes asociados con determinadas identidades étnicoraciales, en un momento y lugar específicos (Broguet 2018a; Rodríguez 2019). En este sentido, resulta fructífera la sugerencia de Taylor (2003, 19-20) acerca de prestar atención a los diversos modos en que las performances "producen, almacenan y transmiten conocimiento" -en cuanto "información, memoria, identidad y emoción”-: por un lado, de manera directa, mediante repertorios de actos corporizados que se transmiten de generación en generación y que "ponen en escena la memoria incorporada”, y por otro, a través de archivos materiales - que existen en "documentos, mapas, textos literarios, cartas, restos 
arqueológicos, huesos, videos, películas, discos compactos”- que resisten el paso del tiempo y producen una distancia entre el momento de producción y el de recepción. Nos interesa analizar así los modos concretos en que actualmente los repertorios y archivos se entretejen y son estratégicamente utilizados en las prácticas de los/as performers para la incorporación de lo ancestral como recurso identitario característico.

Para finalizar esta introducción, queremos aclarar que, en términos metodológicos, nuestra investigación articuló dos instancias complementarias: el relevamiento y el análisis de fuentes documentales (legislaciones, programas culturales y medios de difusión de organismos públicos del área “cultural”) y una extensa experiencia de trabajo de campo etnográfico con grupos tobas o qom de Formosa - desde fines de la década de los noventa- y con colectivos y expresiones afrodescendientes de Santa Fe — desde 2008- A partir del trabajo colaborativo, nos interesa contribuir a los estudios recientes que abogan por la emergencia de un enfoque relacional afroindígena, para comprender así las inscripciones contextuales del giro al multiculturalismo en América Latina (Goldman 2014; Maffia y Tamagno 2011; Restrepo 2007). En nuestro caso, nos interesa sumar a este enfoque los aportes de los estudios de la performance y de la performatividad en una perspectiva de género abordando las prácticas estéticas de estas mujeres indígenas y afrodescendientes que han sido, como nos solían decir, doblemente invisibilizadas.

\section{Indígenas y afrodescendientes en la construcción del Estado nación argentino}

Entre 1873 y 1911, el Estado argentino, en continuidad de sus campañas militares hacia el sur del territorio, emprendió el avance sobre la región noreste, desde el norte santafesino hasta la actual Formosa. En esta región, el interés no estaba centrado en los territorios, sino más bien, como sostenía Victorica, el militar a cargo, en "atraer las tribus al trabajo" (Victorica 1885, 5) y proporcionar “brazos baratos a la industria azucarera y los obrajes de madera” (23). Una vez finalizada esta etapa, entre 1900 y 1930, se establecieron reducciones estatales y misiones religiosas con el objetivo de sedentarizar allí a los indígenas sobrevivientes, incorporarlos como mano de obra, “civilizarlos y evangelizarlos”. Paralelamente a estos procesos, los gobiernos patrocinaron la inmigración, fundamentalmente europea, y fue Argentina el segundo país — después de Estados Unidos- que 
recibió mayor cantidad de inmigrantes en esa época: se calcula que más de seis millones de inmigrantes arribaron en 1930.

En lo que refiere a la población de africanos y afrodescendientes, los estudios historiográficos clásicos han venido reiterando su drástico descenso e incluso su “desaparición” durante el siglo XIX, bajo el argumento de su amplia participación y mortalidad en las guerras de la Independencia (1806-1825) y la guerra del Paraguay (1864-1870), así como en la epidemia de fiebre amarilla de 1871 en Buenos Aires. No obstante, investigaciones más recientes permitieron redimensionar su presencia y develaron que estas hipótesis sobre su temprana desaparición fueron parte de los esfuerzos de las élites políticas e intelectuales por invisibilizar a esta población y producir una sociedad "blanca y europea" (Reid Andrews 1989). Además, como señala Fernández Bravo (2016), en estos análisis quedaron relegados "los complejos procesos de mestizaje que se dieron en las distintas provincias del territorio nacional” (164).

Una de las primeras disrupciones en este imaginario dominante de "nación blanca” se advierte durante los gobiernos de Juan Domingo Perón (19451955). En 1949, con la reforma de la Constitución nacional, se eliminó la alusión al "trato pacífico y la conversión al catolicismo" de los indígenas, con la intención de evitar cualquier discriminación racial o de clase entre los habitantes del país. Asimismo, en 1946, la anterior Comisión Honoraria de Reducción de Indios fue reemplazada por la Dirección de Protección al Aborigen, encargada, entre otras tareas, de adquirir ganado y herramientas para las distintas colonias indígenas que se establecían en el país. También se promovieron leyes como la que prohibía reducir los territorios ocupados o explotados por aborígenes y la que reglamentaba el trabajo indígena para evitar la explotación y el trato desigual al que solían ser sometidos (Martínez Sarasola 1992, 410-416).

En esta época, también adquirió renovada visibilidad otro actor social, llamado despectivamente “cabecita negra” por las élites urbanas. Esta denominación refiere a aquellos jóvenes que, en la década de los cuarenta, comenzaron a migrar desde las provincias más pobres del norte del país, con población mestiza, indígena o negra campesina, hacia la ciudad capital, atraídos por la posibilidad de emplearse como asalariados en la industria que allí se estaba desarrollando. Como destaca Gravano, los contingentes de cabecitas negras aumentaron drásticamente la concentración poblacional, principalmente en Buenos Aires y su conurbano, donde la población llegó a sobrepasar el 50\% del total del país $(1985,87)$. Este sector social se convirtió en uno de los grandes beneficiarios de las políticas de inclusión social del peronismo, así como en el principal artífice de sus triunfos electorales. 
Ratier (1971) señaló cómo la alusión al “color” del rostro de este actor social mostraba la persistencia de configuraciones racistas entre aquellos sectores sociales más acomodados de Buenos Aires que reivindicaban su ascendencia europea. En su relectura de Ratier, Frigerio $(2006,10)$ sugiere que la aparición de esta amenaza a la "blanquedad porteña" significó un nuevo sistema de categorizaciones raciales: a medida que se reducía la cantidad de "negros verdaderos” en la ciudad, crecía la visibilidad de "otros negros” que estaban emparentados semántica y hasta genéticamente con sus precursores. Así, investigaciones posteriores retoman esta perspectiva y destacan cómo el criollo-mestizo-provinciano posee, en mayor medida de lo habitualmente afirmado, ancestros africanos, pues la piel oscura del cabecita negra proviene del mestizaje no solo con indígenas, sino también con población negra (Broguet 2018b; Carrizo 2011; Fernández Bravo 2016; Geler 2016; Grosso 2008; Guzmán 2010).

En el campo de las políticas culturales del peronismo, es significativo analizar cómo se conformó en aquellos años el "repertorio folclórico”, sobre todo el musical y dancístico. Por un lado, el Gobierno promovió la difusión del folclore como parte de la definición de una "cultura nacional y popular", contrapuesta a las anteriores tendencias cosmopolitas del arte de las élites. Así, se financiaron investigaciones folclóricas, se incluyó al folclore en la enseñanza escolar y, a fines de 1949, se promulgó un decreto que obligaba a difundir en lugares públicos y en la radio una proporción igualitaria de música nacional y extranjera, hecho que repercutió en la proliferación de conjuntos de raíz folclórica (Gravano 1985, 90-94). No obstante, al analizar cuáles fueron las expresiones consideradas como músicas y danzas folclóricas de la Argentina, se advierte el predominio de una noción de mestizaje que privilegia la raigambre europea.

Cuando, a mediados del siglo XX, el musicólogo argentino Carlos Vega (1944, 1952) comenzó a documentar las músicas y danzas folclóricas, en sus estudios excluyó a los grupos indígenas y afrodescendientes que existían en el país y consideró que solamente un par de géneros de la región del noroeste andino contenían raíces indígenas (el carnavalito y la baguala) y ninguno afro. Sin embargo, en el caso de Santa Fe, estudios más recientes pudieron rastrear la presencia de expresiones culturales afro (Cirio 2012) e indígenas (Citro 2006) vigentes en esa época en la provincia. A pesar de que los intereses por las tradiciones de cuño hispánico dominaban el imaginario de las investigaciones folclóricas de la época, la presencia negra e indígena fue lo suficientemente relevante como para que hoy podamos reconstruirla a través de diferentes textos y documentaciones.

Retomando nuestra síntesis histórica, entre 1955 y 1983 Argentina sufrió un conflictivo periodo que incluyó sucesivos golpes de Estado, proscripciones al 
peronismo y dictaduras militares, y que excluyó las problemáticas indígenas y afro de la agenda pública. Una excepción fue la realización del primer censo indígena en 1965, bajo el breve mandato del presidente Arturo Illia, del Partido Radical. Posteriormente, aunque a inicios de la década de los setenta comenzaron a gestarse las primeras organizaciones políticas indígenas, la dictadura que se inició en 1976 clausuró muchos de estos procesos. Fue también a inicios de los años setenta cuando se produjeron las primeras investigaciones antropológicas que documentaban las expresiones musicales y dancísticas de los grupos indígenas, gracias al trabajo pionero de Irma Ruiz y Jorge Novati. Con el restablecimiento de la democracia en 1983 y la asunción de Raúl Alfonsín, también del Partido Radical, en 1985 se sancionó la Ley Nacional 23302 de Política Indígena y Apoyo a las Comunidades Aborígenes, hasta hoy vigente.

En relación con las poblaciones afrodescendientes, en 1988 fue fundada en Santa Fe la organización político-cultural Casa de la Cultura Indoafroamericana -en adelante, la Casa-, en una articulación inédita entre los reclamos de los afrodescendientes y las organizaciones indígenas, principalmente mocovíes y qom. En nuestros trabajos de campo, Lucía Molina, fundadora y actual presidenta de la Casa, nos explicaba que sus reclamos políticos iniciales partían de las “condiciones de negación, usurpación, no reivindicación de los negros e indígenas” y que, por esta razón, el nombre subrayaba lo indoafro. La fecha escogida, 21 de marzo, recuerda el Día Internacional contra la Discriminación Racial, en memoria de la Masacre de Sharpeville durante el apartheid sudafricano, lo cual evidencia las conexiones de la Casa con otras organizaciones de Buenos Aires que, hacia los años ochenta, también estuvieron ligadas a este reclamo internacional.

Ya en la década de los noventa, a partir del retorno del peronismo al poder, el presidente Carlos Menem inició un periodo de políticas neoliberales y retracción del Estado, en consonancia con las políticas económicas impuestas por el Fondo Monetario Internacional y otros organismos internacionales, que concluyeron en una profunda crisis económica y política durante los años 2000 y 2001. En esta etapa también se aprecian las primeras influencias de los discursos multiculturalistas promovidos por las organizaciones internacionales. Tales discursos favorecieron la emergencia de pueblos, grupos y expresiones culturales antes invisibilizados, que comenzaron a reclamar derechos en razón de su identidad y que obtuvieron así reconocimientos legales e incluso algunos recursos económicos de los organismos transnacionales y nacionales. Bajo este marco, en 1994 se aprobó una nueva Constitución nacional que incluía por primera vez el reconocimiento de un pasado y un presente "pluricultural” cuyos principales referentes fueron los “pueblos indígenas” —no así los afrodescendientes-, en cuanto se afirmaba su "preexistencia étnica y cultural” frente al Estado argentino y se 
garantizaba "el respeto a su identidad y el derecho a una educación bilingüe e intercultural” (art. 75, inc. 17). No obstante, el reconocimiento legal no se tradujo en una mejor calidad de vida para estas poblaciones. En este sentido, y como han señalado diversos autores, la propuesta del multiculturalismo acerca de la coexistencia y el respeto de todas las culturas por igual ha operado como la contracara de una economía política de la desigualdad que emerge del modelo neoliberal (Grüner 2002; Lacarrieu 2000; Povinelli 2002; Rivera Cusicanqui 2010; Segato 1999; Zizek 1998).

Con relación a los pueblos afrodescendientes, a mediados de la década de los noventa, a través del Banco Interamericano de Desarrollo (BID), líderes afroargentinos participaron del Foro sobre la Pobreza y las Minorías en América Latina y el Caribe, donde se firmó la declaración que sustentó la formación de la Red Afroamérica XXI. A partir de los recursos que ofrecía la vinculación con esta red, en 1997 la afroporteña María Magdalena “Pocha” Lamadrid creó la Fundación África Vive. Ya para el segundo milenio, López (2006) destaca la importancia de la III Conferencia Mundial de las Naciones Unidas contra el Racismo, la Discriminación Racial, la Xenofobia y las Formas Conexas de Intolerancia, celebrada en Durban, Sudáfrica, en 2001. Allí, por primera vez, los afrodescendientes argentinos estuvieron representados en una conferencia a nivel mundial. La declaración final promovió la visibilización de los aportes afro a los respectivos países en el ámbito de la educación y de la política, y la inclusión de afrodescendientes en los censos nacionales. Así, se volvió un instrumento legal para exigir al Estado argentino el reconocimiento de la existencia de una "minoría negra argentina”. A partir de esta conferencia y aunque con discusiones y controversias, se propuso incluir el término afrodescendientes en cualquier documento que tratara la diversidad cultural y reemplazar el de pueblos indígenas por el de pueblos originarios.

En 2003, con otro gobierno peronista, el de Néstor Kirchner, y luego el de su esposa, Cristina Fernández de Kirchner, comenzaron a revertirse muchas de las políticas económicas de la década anterior, a partir de una mayor intervención estatal en la producción y la redistribución económicas y de una creciente integración económica-política y cultural con Latinoamérica. En este contexto, las políticas culturales nacionales evidencian posicionamientos ideológicos que destacan "el carácter multicultural del país” (Bayardo 2008, 17). Esta postura se ha fortalecido sobre todo a partir de 2010, año del bicentenario. En un trabajo anterior (Citro 2017) analizamos la expresión de un imaginario multicultural y popular en los festejos del bicentenario, así como en otros actos de gobierno de esa época que intentaron descolonizar tiempos y espacios claves para la construcción de los imaginarios identitarios nacionales, por ejemplo, ciertos hitos del 
calendario oficial, las imágenes y los nombres que pueblan la sede central de gobierno o el dinero circulante. De esta manera, se ha confrontado parte del imaginario que, desde fines del siglo XIX, construyeron las élites gobernantes acerca de una nación blanca, heredera fundamentalmente de las tradiciones europeas.

\section{El canto ancestral qom en una Formosa diversa y conflictiva}

En la última década, tanto los qom como otros pueblos originarios de esta provincia fueron objeto de políticas públicas que incluyeron programas de construcción de viviendas, centros de salud y educación, y diversos planes de asistencia social. No obstante, tanto en esta como en otras provincias del norte argentino, persistieron los conflictos por la propiedad de la tierra y las problemáticas por el avance de la frontera agrícola - principalmente por el cultivo de soja- que condujo al desmonte de los bosques nativos y a la reducción de los territorios de caza y recolección y de los cultivos para el autoconsumo. Además, muchas de las políticas asistenciales del Estado se entrelazaron con redes de clientelismo político local, lo que profundizó las situaciones de desigualdad. En este complejo escenario, algunos grupos qom empezaron a generar modalidades propias de organización política que involucraron asambleas, cortes de ruta ${ }^{3}$ y la formación de asociaciones independientes del Estado y de los partidos políticos tradicionales. En muchos casos, la respuesta del Estado provincial incluyó la deslegitimación y la persecución de los nuevos líderes, la criminalización de la protesta social, la represión y el abuso de las fuerzas policiales (Cardín 2013; Iñigo Carrera 2011; Vivaldi 2008).

En este conflictivo contexto, el gobierno formoseño empezó a impulsar políticas culturales que intentaban enfatizar el carácter pluri- o multicultural de la provincia. Una de las primeras transformaciones fue la reforma de la Constitución provincial en 2003, en la que se reafirma "la auténtica identidad multiétnica y pluricultural” de la provincia (preámbulo) y se alude a la "preexistencia de los pueblos aborígenes que la habitan” (art. 79, cap. 4); asimismo, el Estado se compromete con el "desarrollo integral de la cultura”, a partir de la "defensa,

3 Así se denomina en Argentina a una modalidad de protesta que consiste en obstruir las vías de acceso, con personas que se manifiestan políticamente y recurren a diversos elementos, como encendido de fogones, formación de barricadas, etc. 
preservación e incremento del patrimonio cultural” (art. 92, inc. 3). En 2004, la Subsecretaría de Cultura provincial organizó el I Encuentro de Pueblos Originarios de América como una apuesta por el patrimonio cultural indígena. Un año después, en el marco del Cincuentenario de la Provincialización de Formosa, la Subsecretaría de Cultura comenzó a promover las presentaciones artísticas de algunos músicos indígenas como Ema Cuañeri, Romualdo Diarte y Pilancho González. No obstante, con la intensificación de los conflictos territoriales y políticos con los líderes indígenas, los encuentros dejaron de realizarse y el apoyo estatal a estos artistas se tornó cada vez más errático, hasta prácticamente desaparecer en la actualidad (Citro y Torres Agüero 2012; Iñigo Carrera 2011).

En suma, si bien desde los discursos oficiales se intenta legitimar un "ser formoseño multicultural” que responde a las políticas globales y nacionales de promoción del multiculturalismo y la patrimonialización, en su implementación práctica estas políticas han sido fuertemente dependientes de los vaivenes políticos y, en especial, de los conflictos entre los diferentes grupos sociales. Por eso, tal como en trabajos anteriores (Citro y Torres Agüero 2012, 2015), consideramos que estas políticas han sido utilizadas estratégicamente para fortalecer la imagen de una administración que adheriría a los mandatos globalizados impuestos a las democracias y para enmascarar así el alto grado de conflictividad que aún se mantiene con los grupos indígenas que luchan por sus reivindicaciones territoriales, económicas y político-sociales.

Veamos cómo, en este complejo contexto, Ema Cuañeri reivindica lo que denominó canto ancestral qom. Ema suele autodefinirse como cantora, actriz y docente, y en muchas de nuestras conversaciones nos explicaba que la música que practica podría llamarse ancestral, por ser "la que se transmitió de generación en generación”, gracias a las "recopilaciones que tenemos de nuestras familias... de nuestros ancestros” (comunicación personal, septiembre de 2014). Esta música refiere a los géneros previos a la conversión religiosa de los qom a distintas modalidades del cristianismo: principalmente, el denominado evangelio - con influencias pentecostales-, el anglicanismo y, en menor medida, el catolicismo. Este proceso condujo al abandono de la ejecución pública de algunos géneros vinculados a rituales y festividades del pasado que fueron duramente criticados por las iglesias, como los cantos-danzas de los jóvenes solteros, los rituales de iniciación femenina o los cantos chamánicos con la sonaja de calabaza. Pero ni las críticas ni las discontinuidades en las prácticas impidieron que algunos rasgos musicales de estos géneros persistieran en la música evangélica, lo que dio lugar a procesos de hibridación musical y coreográfica (Citro 2009; Ruiz y Citro 2002).

A pesar de la vitalidad y la hegemonía que hoy adquiere este movimiento evangélico entre los qom formoseños y de la deslegitimación que este provocó 
sobre sus músicas y danzas anteriores, a las que suelen llamar "antiguas”, en 2005 se realizaron las primeras - y por ahora únicas - grabaciones en CD, gracias al apoyo de organismos de cultura nacionales y provinciales. En este sentido, consideramos que la elección del término ancestral les ha permitido a Ema y otros músicos diferenciarse de las connotaciones negativas que posee la expresión música y danza antiguas entre los qom evangélicos, en oposición a "lo civilizado y moderno" (Citro 2009).

Así, en 2005 Ema participó en la creación del CD Cuatro mujeres: cantos de la tierra ${ }^{4}$, financiado por el Fondo Nacional de las Artes y la ONG Asociación Civil Runa Wasi, que incluye, además de los cantos de Ema, los de otras tres mujeres indígenas pertenecientes a las comunidades quechua, kolla y mapuche. Posteriormente, frente a la falta de apoyo del gobierno provincial, tanto Ema como Romualdo Diarte profundizaron sus vínculos con investigadores académicos. Tal es el caso de las colaboraciones con nuestro equipo, que dieron como fruto la realización de dos videos y de un libro en coautoría sobre música y danza qom ${ }^{5}$. Más recientemente, Ema también comenzó a colaborar con otros músicos formoseños no-indígenas, con quienes ha realizado diversas presentaciones y giras.

A continuación, profundizaremos en los sentidos que Ema ha construido en torno a la noción de ancestralidad. Si bien su madre "no quería que ella retomara la cultura”, con su padre sí hablaban y cantaban en idioma toba, y de ese entorno familiar surgió su preocupación por evitar que se “pierdan” esas canciones:

Mucho tiempo sufrí por eso, porque pensaba que se iba a perder: ¿cómo no se van a cantar más esas canciones? Creo que eso fue lo que me movilizó a cantar. Mi papá cantaba; él me enseñó mucho a interpretar, a valorar el canto. A mí las canciones me salen del alma. (Ema Cuañeri, comunicación personal, marzo de 2014)

Ema también nos contaba que se dedica a "transmitir lo ancestral, repetir lo que hacían, porque trato de hacer tal cual era antes”. Esta perspectiva también es expresada en el encabezamiento de su curriculum vitae, donde escribe:

A la memoria de las mujeres indígenas he dedicado por más de tres décadas la recuperación histórica del canto del pueblo qom. Nosotras elevamos nuestras voces haciendo un llamado por el respeto a la madre tierra, la vida, el territorio y nuestros derechos ancestrales. Con este llamado

4 Disco disponible en: https://www.youtube.com/watch?v=-iNoWaU2cQY

5 Los cortometrajes audiovisuales ÑamaqtaGa ca César (Visitando a César) (Torres Agüero et al. 2007a) y Potai Napokna (Colonia La Primavera) (Torres Agüero et al. 2007b) se encuentran disponibles en http://www.antropologiadelcuerpo.com/index.php/cortos/videos. El libro Memorias, músicas, danzas y juegos de los qom de Formosa (Citro et al. 2016) puede descargarse en http:// publicaciones.filo.uba.ar/memorias-m\%C3\%BAsicas-danzas-y-juegos-de-los-qom 
buscamos aunar esfuerzos para una mejor conservación de esta filosofía, sus valores éticos, estéticos y espirituales, fundamentados en la cosmovisión de nuestros ancestros. Las mujeres qom, junto con las nuevas generaciones que damos a luz, somos las guardianas y responsables de mantener, trasmitir, proteger y desarrollar los valores que nos identifican como pueblo. De allí la importancia de las mujeres en el accionar histórico y en las luchas ligadas a la mantención de la vida, un papel que rara vez se nos reconoce.

En la narrativa que Ema construye para presentarse como artista, las mujeres, en su asociación con la Madre Tierra, el territorio y la generación de la vida, son revalorizadas como transmisoras y protectoras de la cultura qom. Sin embargo, en la narrativa biográfica que Ema construyó durante nuestras entrevistas, fue su padre - y no su madre- quien le transmitió los cantos.

Por otra parte, en su presentación ${ }^{6}$ en el CD Cuatro mujeres (2005) también destaca esta tarea de transmisión de lo ancestral. Desde hace años "recibe” los cantos ancestrales de sus mayores y generosamente los comparte. Tiene la inmensa tarea de recuperar los mensajes de sus ancestros y transmitirlos. Todos los temas que aquí interpreta pertenecen a la memoria colectiva del Pueblo Qom.

En relación con esta importancia de los ancestros, cabe destacar que el primer tema que Ema canta en el CD, luego de un breve relato sobre sus orígenes familiares, es una canción del linaje de su padre y otra del linaje de su madre. Los dos cantos que siguen refieren a historias sobre cómo se formaron las estrellas y el canto para llamar al picaflor, "encargado de juntar en las flores las almas de los muertos y llevarlas a su morada final” (Cuatro mujeres 2005). El último canto es una canción qom para dormir a los bebés. Estos temas son precedidos por explicaciones verbales en español, que aparecen también escritas en el interior del CD. Dicha modalidad ya había sido adoptada por el grupo Chelaalapi, un coro toba de la vecina provincia de Chaco que realizó diferentes grabaciones desde los años noventa, las cuales inspiraron el trabajo de Ema. Tal es el caso de la canción para dormir al bebé, que ya había sido grabada anteriormente por ese coro. En suma, entre sus memorias, lo que "le sale del alma” y los archivos históricos que constituyen las grabaciones de Chelaalapi, Ema fue construyendo el repertorio para sus performances y para este nuevo archivo que es su CD.

Finalmente, en lo que refiere a la imagen corporal de Ema, encontramos que aparece en el CD con una fotografía en primer plano, vestida con un tejido artesanal de chaguar (planta nativa de fibra textil, de la familia de la Bromiliacea)

6 Véase https://soundcloud.com/ema-cua-eri/presentaci-n?in=ema-cua-eri/sets/cuatro-mujeres-cantos-de-la-tierra 
en tonalidades marrones, con el pelo negro suelto y la mirada hacia atrás, como "contemplando a los ancestros... para que lo de atrás no se pierda", como nos explicó en una de nuestras conversaciones.

Esta vestimenta, así como el recurso de explicar los orígenes de cada canto y remarcar su carácter ancestral, son utilizados por Ema tanto en el CD como en sus performances artísticas en diferentes escenarios. Probablemente, tales elementos permiten enfatizar una cierta "autenticidad" indígena, a través de "expresiones originarias” o ancestrales que han sido transmitidas de generación en generación. Incluso algunas de estas parecen evidenciar una cierta exotización de lo indígena que resaltaría su otredad y asociación al pasado: tal es el caso de la vestimenta que luce Ema en sus actuaciones - un tejido tradicional que hoy se comercializa como artesanía, pero que no habría sido utilizado como vestimenta - o también el énfasis en el vínculo con una "naturaleza” prístina, especialmente de las mujeres. Como ha sugerido Ramos (1998), en estos casos parece apelarse a imágenes de un indígena hiperreal, que no necesariamente se condicen con las/os indígenas contemporáneos y que, en parte, estarían dirigidas a satisfacer los imaginarios de utopías primitivistas de algunos espectadores "blancos” y "no-blancos".

\section{El candombe "del Litoral" entre las/os afrodescendientes de Santa Fe}

Desde su creación, Lucía Molina y las/os integrantes de la Casa se dedicaron al trabajo de lectura, revisión de archivos y entrevistas sobre la población negra en el continente. También ensayaron formatos que articularon diferentes lenguajes estéticos, como una puesta teatral llamada Los negros de Santa Fe y talleres teórico-prácticos de candombe afrouruguayo, junto a un músico uruguayo afrodescendiente criado en Santa Fe.

La Casa se ubica en la zona oeste de la ciudad de Santa Fe, en una vivienda que fue el hogar materno-paterno de Lucía Molina. Durante la segunda mitad del siglo XX, como parte de un proceso tendiente a la modernización del tejido urbano, en la zona se implementaron planes de vivienda destinados a familias trabajadoras, entre las cuales había algunas compuestas por afrodescendientes, como los Molina. Fue justamente en esta zona donde se realizó en 2005 la primera Prueba Piloto de Autopercepción de Afrodescendientes, que se proyectaría hacia el Censo Nacional del 2010. Así, en el mencionado censo se acordó el uso de la 
categoría afrodescendiente y sus resultados, aunque muy cuestionados por serias falencias en su aplicación, arrojaron un 0,4\% de la población nacional.

Durante estos años, en Santa Fe comenzaron a apreciarse algunas políticas culturales emprendidas desde el Estado provincial y municipal, en conjunto con la Casa, tendientes al reconocimiento simbólico de la población afrodescendiente en la historia local. En 2009, en el marco del Año Internacional de los Afrodescendientes, el Concejo Deliberante aprobó la nueva denominación para un espacio público del casco antiguo de la ciudad: este pasó de llamarse Paseo de las Dos Culturas - en alusión a la indígena y la europea- a Paseo de las Tres Culturas, incluyendo así una “tercera raíz”, la de los africanos, no reconocida hasta ese momento. Este espacio comenzó a ser sede de diferentes eventos organizados por agrupaciones afrodescendientes que se identifican como del tronco colonial, con apoyo de instituciones gubernamentales, gremiales y universitarias.

Recién en 2011 se hizo la inauguración oficial del Paseo con una placa conmemorativa y con diversos espectáculos en torno al candombe: los integrantes de la Casa, junto a otros invitados, ejecutaron candombes litoraleños; la organización de afroporteños Misibamba hizo lo propio con candombe porteño y un grupo santafesino de jóvenes con candombe afrouruguayo. Cabe aclarar que la expresión afroargentinos del tronco colonial comenzó a ser usada por un sector del movimiento afro en Argentina hacia fines del 2000, en busca de articular su adscripción étnico-racial y nacional y legitimarla con esta referencia a su antigüedad histórica; de este modo, también se ha ido diferenciando de otros procesos migratorios de población afroamericana y africana más recientes.

También en 2011, con el apoyo de la Cámara de Diputados de la provincia de Santa Fe, se editó el libro Una historia a contramano de la "oficial”: Demetrio Braulio Acosta "el Negro Arigós” y la Sociedad Carnavalesca Negros Santafesinos (López 2011). Este trata de un afrodescendiente nacido en Paraná a finales del siglo XIX y radicado en Santa Fe desde comienzos del XX, quien tuvo un papel relevante en la cultura popular santafesina. Desde principios de siglo XX hasta 1950, Demetrio dirigió la Sociedad Coral Carnavalesca Negros Santafesinos, compuesta mayormente por afrodescendientes, que ejecutaban sus candombes cantados con guitarras, violines y tambores.

En estos últimos años, también se desarrolló una serie de políticas museísticas tendientes a revertir la total ausencia de representación de africanos y afrodescendientes en la historia local, especialmente en el Museo Etnográfico y Colonial Juan de Garay, el Parque Arqueológico Santa Fe La Vieja y el Museo Histórico Provincial Brigadier General Estanislao López. A su vez, las iniciativas de Atardecer en los Museos o La Noche de los Museos, organizadas por el Ministerio de Cultura e Innovación de la provincia, convocaron a la Casa. Más 
recientemente, la Universidad Nacional del Litoral organizó actividades de difusión y debate de la realidad actual de algunos grupos de afrodescendientes. Sin embargo, estas iniciativas muchas veces no trascienden los "reconocimientos simbólicos”, como también lo han planteado Frigerio y Lamborghini (2011) para el caso de Buenos Aires.

En el contexto de estas reivindicaciones surgen los procesos de recreación de los denominados candombes del Litoral. La recreación de este género musical y dancístico forma parte de una historia común de intercambios y desplazamientos de personas, prácticas y objetos entre las vecinas ciudades de Santa Fe y Paraná, provincia de Entre Ríos (Broguet 2019). El barrio del Tambor o del Candombe es el nombre con el que se conoció, hasta mediados del siglo XIX, a una zona anegadiza del norte de la ciudad de Paraná que se conformó, según categorías de la época, con pobladores negros, pardos y morenos, en su mayoría libres o libertos que habían accedido a esas tierras.

Después de más de un siglo, a inicios de los 2000, un grupo de jóvenes de sectores medios, que no se reconocían como afrodescendientes y que participaban de un taller de candombe afrouruguayo en Paraná, comenzó a indagar y a hacer circular relatos sobre este antiguo barrio, como parte de una trama histórica que describían como "oculta” y "escondida”. Así, con la intención de traer al presente esa historia, el grupo organizó el primer contrafestejo previo al 12 de octubre, en Paraná, y empezó a vincularse con Lucía Molina y con la Casa ${ }^{7}$ (Broguet, Picech y Rodríguez 2014).

En 2005 uno de los músicos coordinadores de este taller recibió una beca del Fondo Nacional de las Artes para estudiar aspectos de la cultura afro (afroargentina y afrouruguaya) en ambas márgenes del Río de la Plata. A partir de esta iniciativa, convocó a músicos paranaenses y santafesinos - que ya eran practicantes de candombe afrouruguayo- para iniciar una investigación musical e histórica en torno al legado afro en el Litoral argentino y, más específicamente, sobre cómo habría sido el universo sonoro del barrio del Tambor de Paraná en el siglo XIX. Esto derivó en un proceso al que los músicos denominan recreación de la música afrolitoraleña, con base en registros históricos escritos - sobre todo crónicas, descripciones periodísticas y letras de canciones-, pero en ningún caso material estrictamente sonoro. Como iremos viendo, en este proceso se fueron articulando tanto practicantes de candombe afrouruguayo no afrodescendientes como activistas afroargentinos/as; hasta hoy, tanto unos como otros

Los primeros contrafestejos se realizaron en Argentina en 1992, en rechazo de los quinientos años de la denominada conquista o descubrimiento de América. Estos eventos fueron impulsados por organizaciones de pueblos indígenas y, en menor medida, del movimiento afrodescendiente. 
realizan alternativamente candombe afrouruguayo y recreaciones de estos candombes del Litoral (Broguet 2018a, 2019) ${ }^{8}$.

Con la idea de que esta música no podía ser ejecutada con instrumentos modernos, en paralelo, el grupo inició la construcción de tambores unimembranófonos de tronco ahuecado, a los que incorporaron accesorios de hueso (como quijada de caballo), metal (triángulo) y semillas (chequeres de mate) ${ }^{9}$. A diferencia de los tambores del candombe afrouruguayo - ejecutados con palo y mano-, estos tambores se percuten con las manos, lo cual, según Cirio (2007), es característico del candombe porteño, al que estos músicos de Paraná y Santa Fe tomaron como referencia.

En 2008, con el apoyo del Programa Identidad Entrerriana, orientado a la divulgación y la revalorización del patrimonio cultural, el grupo logró editar el CD multimedia Tangó de San Miguel: candombes del Litoral argentino ${ }^{10}$. En su contratapa dice que el trabajo cuenta con "documentación histórica y antropológica referente a la temática afroargentina”, y se ofrece una selección de notas periodísticas, fragmentos de artículos académicos, crónicas antiguas y fotos. La tapa del CD es una fotografía en blanco y negro de la cúpula de la primera capilla de la iglesia San Miguel, ubicada en la zona del antiguo barrio del Tambor ${ }^{11}$. En consonancia con este interés por lo afro como algo “escondido" u “oculto”, la imagen tiene en primer plano una construcción antigua, con señales de abandono, que no es visible para el público en general, pues solo se accede a ella a través de un pasillo trasero. La contratapa vuelve a hacer referencia al antiguo edificio, en este caso, con una imagen de la puerta de ingreso, también abandonada.

Para este proyecto, los jóvenes convocaron a Lucía Molina y, con ella, recrearon una canción tradicional de la Sociedad Coral Carnavalesca Negros Santafesinos, a partir de un registro de Agustín Zapata Gollán (1966) de la década de los cuarenta. Aquí transcribimos su versión:

En este sentido, como sostuvimos en un artículo previo (Broguet, Picech y Rodríguez 2014), en el caso de Santa Fe no ha habido una comunidad afrouruguaya migrante que dispute las reapropiaciones y las resignificaciones del candombe desplegadas por practicantes argentinos/as, cuestión que sí ha sucedido, en cambio, en Buenos Aires y que ha sido analizada por otros autores que localizaron allí sus investigaciones (Domínguez 2007; Lamborghini 2015, 2019).

9 Varios recursos que aparecen en estos candombes se basan en las investigaciones de Cirio (2002) sobre la charanda en Corrientes como antecedente regional de prácticas musicales de procedencia afro.

10 Según Rossi (1926), el término tangó es de origen africano. En el Río de la Plata los tangos "englobaban local, instrumentos y baile, y esta manera de interpretar fué sujerida [sic] por los mismos negros, que titulaban a sus reuniones por el acto principal de ellas: 'tocá tangó' (tocar tambor)" (144).

11 El enlace al disco es https://www.youtube.com/watch?v=MInl6lAXUHE [N. del E.] 
Oixa, musimba, musimba, molena, molena, molá, que vende escoba y plumelo, y nadie le quiele complá. Macumbalibá, balicumba, licumba, libá, una molena que quiele bailá.

Ooooixá, ooooixá, oooixá, musimba, molena, molá.

Macumbalibá, balicumba, licumba, libá.

Según analiza Cirio $(2012,18)$, este canto emula el bozal, un tipo de "habla propia de los negros en la esclavitud", que reemplaza la "r por la l en la lengua española” y posee además gran cantidad de palabras en algún idioma africano que aún no ha sido identificado. Sin embargo, en la versión discográfica, se descartó el bozal y se escogió ejecutarla según el español actual. Además, se utilizó el término orisá, en alusión a las entidades propias de los cultos religiosos yorubas que llegaron a diferentes regiones de América con el tráfico de esclavizados. Estas referencias religiosas son reforzadas en las performances de danza que acompañan las presentaciones del CD, mayormente protagonizadas por mujeres de la Casa, sobre todo en sus vestuarios, con colores y accesorios que remiten a entidades sagradas femeninas como Oxum o Iemanjá. Así, predomina una estética vinculada a un imaginario colonial, en el cual la vestimenta femenina se caracteriza por polleras anchas, delantales y pañuelos en la cabeza. Los bailes también retoman cierta gestualidad de los orixás afrobrasileños y un conjunto de movimientos provenientes de otras performances culturales como el candombe afrouruguayo, afroporteño e incluso la propia cumbia santafesina (Broguet 2018b).

La grabación del CD comienza con sonidos de voces que insinúan una muchedumbre y la irrupción del canto de Lucía. El término orisá se prolonga en el tiempo como una invocación, hasta recibir la respuesta de un coro femenino con el cual se introducen los tambores, el triángulo y las semillas. La canción asume una estructura responsorial (coro-solista), una característica propia de la música afroamericana (Frigerio 2000; entre otros). En las conversaciones y entrevistas con Lucía nos contaba que, al leer la letra recopilada por Zapata Gollán, "la tarareé de una manera” y esa “inspiración [me] salió desde el alma”, lo que también sugiere una conexión ancestral con ese acervo. En la búsqueda por comprender este recuerdo, Lucía fue hilando argumentos históricos y también biológicos, apelando a un origen que, pese al paso del tiempo, los olvidos y las interrupciones en el traspaso generacional, se “inscribiría en el ADN” como 
una marca indeleble. Así, Lucía nos explicaba: “[los] afro genéticamente tenemos cosas que traemos y no sabemos hasta que las descubrimos [...] sabemos que es un mundo mágico el nuestro, que hay muchas cosas que se pierden en el habla, pero no en los instintos”. A diferencia de lo sucedido con Ema, Lucía nos contó que con su padre no tuvo una “comunicación ancestral”, un saber explícitamente transmitido de generación a generación en torno a una identidad negra. Así, la forma de ir reconociéndose como afrodescendiente fue inicialmente a partir de sus rasgos corporales, porque desde pequeña ella percibía que "era distinta”: "Yo no puedo pasar desapercibida, yo soy negra, negra”, nos decía.

Como ocurrió con muchos afroargentinos, Lucía explica que el corte generacional en parte se vinculó con las aspiraciones de sus padres con respecto a su futuro. Pese a que su padre participaba de los carnavales, a ella, hija única y "muy mimada”, "no la dejaban”. Su familia era "de origen humilde” y sentía que siempre la guardaron "en una caja de cristal”. Así, fomentaron sus estudios como algo imprescindible "para avanzar en la vida” y, en parte, suspendieron la conexión con el resto de sus familiares, con lo cual la transmisión de prácticas y creencias vinculadas a una posible historia en común como negros se vio interrumpida. Para subsanar esas omisiones y silencios familiares, Lucía se volcó a estudiar la temática "intelectualmente": "Lo que adquirí fue en base a la intelectualidad, de investigaciones, de las charlas que tuve con distinta gente y comparando”. Lucía también reconoce que, en su búsqueda de una ancestralidad negra, la música y el baile ocuparon un lugar de relevancia: "En la época que había empezado la televisión acá y pasaban programas de Centroamérica de artistas, me gustaba ver todo lo que sea negro; aprendí a bailar jazz, todo lo que sea danza, [...] música brasilera”. En particular, Lucía señala lo significativas que fueron sus primeras experiencias con los tambores de candombe afrouruguayos hacia fines de la década de los noventa, por "el sentimiento que le despertaban" y la “conexión” que establecían “con su raíz”.

En ese marco, la invitación a "recrear candombes propios” para la edición del CD fue para ella un "autodescubrimiento". La recreación de este candombe "propio" - contrapuesto al estilo afrouruguayo, concebido como "ajeno", en términos de fronteras nacionales jurídico-políticas- operó como un recurso cultural de visibilización de la afrodescendencia y contribuyó a la organización político-cultural de los afrodescendientes de Santa Fe, como también a la divulgación de estas expresiones entre jóvenes pertenecientes a sectores medios, no necesariamente afrodescendientes. 


\section{Reflexiones finales}

A partir del análisis comparativo, constatamos la importancia de la reivindicación de lo ancestral en las prácticas estéticas y significaciones construidas por performers indígenas y afrodescendientes de Argentina, en el contexto de los procesos de multiculturalismo y activación patrimonial propiciados por las políticas culturales.

Tanto Ema como Lucía apelan a un conocimiento ancestral que interpretan como un antiguo legado cultural incorporado, encarnado, que hoy les permite legitimarse en sus roles de divulgadoras de sus respectivas pertenencias étnicoraciales. Para ello, ambas participan en procesos de recuperación de repertorios y archivos históricos que, a su vez, se transforman en el mismo proceso creativo. Así, se generan nuevos recursos que pasan a formar parte del bagaje cultural disponible, tanto en la forma de repertorios originales como de nuevos archivos. Tal es el caso de la producción discográfica, que es especialmente valorada como un modo de resguardar y a la vez transmitir ese legado ancestral. Vemos entonces cómo aquello que las/os performers consideran lo propio, lo ajeno y lo recreado se mezcla en este proceso, en el cual intervienen historias familiares y regionales, pero también investigaciones folclóricas, históricas y antropológicas.

No obstante, encontramos algunas diferencias en los modos en que se ha producido performáticamente esa "ancestralidad". En el caso de Ema, los llamados cantos ancestrales fueron reconstruidos principalmente mediante repertorios encarnados, es decir, incorporados a través de las memorias sonoras de su escucha, en el contexto de sus vivencias familiares y con su grupo étnico, y también recurriendo a algunos archivos recientes, como las grabaciones del coro Chelaalapí. Para Lucía, en cambio, existieron pocas posibilidades de explorar este tipo de repertorios familiares, por lo cual sus reconstrucciones estuvieron mediadas por archivos, en especial por investigaciones llevadas a cabo por historiadores y antropólogos, así como por jóvenes músicos, y por repertorios que se relocalizaron en Argentina, mayormente de la mano de migrantes afroamericanos de países limítrofes, como sucedió con el candombe afrouruguayo.

Consideramos que estas estrategias son resultado de los distintos procesos de invisibilización que atravesaron indígenas y afrodescendientes en Argentina. En el caso qom, a pesar de que los procesos de colonización y evangelización condenaron la celebración de muchos rituales colectivos, y por ende de sus músicas y danzas, el ámbito familiar permitió su relativa continuidad, a partir de las memorias de algunos adultos y ancianos que, en ciertas ocasiones, podían recrear estas expresiones y posibilitaron así su transmisión intergeneracional. Cuando 
el contexto sociocultural fue más favorable al reconocimiento de la diversidad cultural, Ema pudo retomar esas memorias familiares circunscriptas al ámbito doméstico, combinarlas con los archivos producidos por otros músicos qom y montar sus propios espectáculos, a la vez que crear nuevos archivos.

En el caso de las/os afrodescendientes de Santa Fe, en cambio, la violencia del proceso de blanqueamiento penetró con mayor fuerza, incluso en los ámbitos familiares, lo que propició el silencio y el abandono de la transmisión cultural intergeneracional. Así, para Lucía, la reconstrucción de los candombes litoraleños fue posible gracias a una búsqueda intelectual en los archivos - sobre todo textuales y visuales - y expresiva, mediante la indagación de prácticas culturales afro transnacionalizadas, así como a una cierta intuición que, en sus palabras, le vino “desde el alma” y estaría inscrita “en sus genes”, y le permitió la conexión con ese pasado olvidado. En este sentido, es interesante destacar cómo estas “intuiciones” son concebidas, por un lado, bajo la persistente influencia de un paradigma racializador que concibe las expresiones culturales como inscritas en un cuerpo-alma, pero también como fruto de relaciones socioafectivas específicas que se potencian a partir del contacto vivencial con los archivos, en el marco del interés y la revalorización que produce un grupo de jóvenes músicos que no se reconocen como afrodescendientes.

Finalmente, hemos destacado cómo estos procesos locales son parte de un marco nacional y global de promoción del multiculturalismo y la patrimonialización que ha tendido a enfatizar y exotizar las expresiones indígenas y afrodescendientes, ligadas principalmente al pasado, por sobre la expresión de las problemáticas y expresiones culturales contemporáneas de estos grupos subalternizados. Como sugiere Povinelli (2002), a diferencia de la dominación colonial que, según Franz Fanon, inspiraba a los colonizados a identificarse con los colonizadores, la dominación multicultural del liberalismo tardío opera por contraste, inspirando a los subalternos y a las minorías a identificarse con el objeto imposible de una identidad “auténtica”, “tradicional”, “pre-nacional, domesticada y libre de conflictos” (13-20).

No obstante, nuestro estudio también muestra de qué manera las recreaciones sonoro-corporales de la "ancestralidad" han sido estratégicamente utilizadas por Ema y Lucía como recursos para visibilizar sus propias demandas político-sociales como mujeres integrantes de colectivos - pueblos originarios y afrodescendientes, respectivamente-y sus luchas a través del tiempo. Así, ellas se han apropiado de estos significantes claves de las políticas culturales actuales, los han tensionado y les han imprimido sus propias significaciones a partir de sus historias de vida y elecciones estéticas. Por ello, en estos usos de la "ancestralidad” se evidencian tanto las huellas de estas interpelaciones multiculturalistas 
y patrimoniales que propician la reproducción de ciertos estereotipos culturales sobre lo indígena y lo afro como la agencia de estas mujeres que, al re-crear con sus propias modulaciones performáticas algunos de esos esencialismos estratégicos (Briones 2005b; Spivak 1987), también crean espacios de legitimidad no solo frente a la sociedad hegemónica, sino también para ellas mismas frente a sus colectivos de pertenencia.

En suma, en este campo cultural ambivalente e híbrido conformado por las políticas culturales de nuestras sociedades poscoloniales (Bhabha [1994] 2002), las recreaciones sonoro-corporales de lo ancestral se instituyen como lo propio, lo heredado y lo legítimo. Y en este complejo campo, estas y otras mujeres performers indígenas y afrodescendientes oscilan performativamente entre lo que han recibido y lo que innovan, lo que reproducen y lo que subvierten, lo que desconocen, lo que rechazan y lo que crean; entre las coacciones y las elecciones que delimitan el flujo de sus vidas y, dentro de ellas, de sus prácticas artísticas.

\section{Referencias}

Annecchiarico, Milena. 2018. "El patrimonio cultural afroargentino: un análisis del programa ‘ruta del esclavo' Unesco en Argentina”. Revista del Museo de Antropología 11 (1): 229-240. https://doi.org/10.31048/1852.4826.v11.n1.17543

Bayardo García, Rubens. 2008. "Políticas culturales: derroteros y perspectivas contemporáneas”. Revista de Investigaciones Políticas y Sociológicas 7 (1): 17-29. https://www.redalyc. org/articulo.oa?id=38070103

Bhabha, Homi. (1994) 2002. El lugar de la cultura. Buenos Aires: Manantial.

Briones, Claudia. 2005a. "Formaciones de alteridad: contextos globales, procesos nacionales y provinciales”. En Cartografías argentinas: políticas indígenas y formaciones provinciales de alteridad, compilado por Claudia Briones, 9-36. Buenos Aires: Antropofagia.

—. 2005b. (Meta)cultura del estado-nación y estado de la(meta)cultura. Jigra de Letras 4. Popayán: Editorial Universidad del Cauca.

Broguet, Julia. 2018a. "Itinerarios del candombe en el sur del Litoral argentino”. En Memoria e identidad en las artes escénicas de Rosario, compilado por Juan Bautista Lucca y Leonardo di Lorenzo, 127-170. Rosario: Editorial Glosa.

—. 2018b. “'Mujeres, negras y argentinas': articulaciones identitarias entre mujeres afrodescendientes de la ciudad de Santa Fe (Argentina)”. Estudios sobre Culturas Contemporáneas, 3. ${ }^{\text {a }}$ poca, 23 (46): 81-109. https://www.redalyc.org/articulo.oa?id=31653529006 
- 2019. “Salir de la blanquitud': candombe afrouruguayo y categorías étnico-raciales en Paraná, Santa Fe y Rosario (fines siglo XX a 2015)”. Tesis de Doctorado en Antropología, Facultad de Filosofía y Letras, Universidad de Buenos Aires, Buenos Aires.

Broguet, Julia, María Cecilia Picech y Manuela Rodríguez. 2014. “'Argentina tiene un gran problema de identidad...': resignificando lo propio y lo ajeno del candombe en el Litoral argentino”. En Experiencias de la diversidad, compilado por Cristina di Bennardis, 350-364. Rosario: UNR Editora.

Butler, Judith. 1999. Gender trouble: feminism and the subversion of identity. Nueva York: Routledge.

Cardín, Lorena. 2013. "La comunidad qom Paotae Napoqna Navogoh (La Primavera) y el proceso de lucha por la restitución de su territorio". Ponencia presentada en la X Jornada de Sociología, Universidad de Buenos Aires, Buenos Aires, 1. ${ }^{\circ}$ al 6 de julio de 2013.

Carrasco, Morita y Claudia Briones. 1996. La tierra que nos quitaron. Buenos Aires: IWGIA.

Carrizo, Marcos. 2011. Córdoba morena (1830-1880). Córdoba: Asociación Cooperadora de la Facultad de Ciencias Económicas de la UNC.

Chaves, Margarita, Mauricio Montenegro Riveros y Marta Zambrano. 2010. "Mercado, consumo y patrimonialización cultural”. Revista Colombiana de Antropología 46 (1): 7-26. https://doi.org/10.22380/2539472X.971

Cirio, Norberto Pablo. 2002. "Prácticas musicales de procedencia afro en el culto a San Baltazar. La 'charanda' de Empedrado (provincia de Corrientes, Argentina)”. Revista Musical Chilena 197: 9-38. https://revistamusicalchilena.uchile.cl/index.php/RMCH/article/view $/ 12618 / 12918$

—. 2007. “¿Cómo suena la música afroporteña hoy? Hacia una genealogía del patrimonio musical negro de Buenos Aires”. Revista del Instituto de Investigación Musicológica Carlos Vega 21: 84-120. https://repositorio.uca.edu.ar/handle/123456789/959

-. 2012. "La presencia afro en la producción académica argentina. El caso del Cancionero de Santa Fe, de Agustín Zapata Gollán”. Música e Investigación 20: 131-159. http://bibliofba. unlp.edu.ar/meran/opac-detail.pl?id1=22349\#.X_zID-hKjIU

Citro, Silvia. 2006. La Fiesta del 30 de Agosto entre los mocovíes de Santa Fe. Buenos Aires: Universidad de Buenos Aires / Facultad de Filosofía y Letras.

-. 2009. Cuerpos significantes: travesías de una etnografía dialéctica. Buenos Aires: Biblos.

—. 2017. "Cuando 'los descendientes de los barcos' comenzaron a mutar. Corporalidades y sonoridades multiculturales en el Bicentenario argentino”. AIBR: Revista Iberoamericana de Antropología 12 (1): 53-76. http://www.aibr.org/antropologia/netesp/numeros/1201/120104.pdf

Citro, Silvia y Adriana Cerletti. 2009. “'Aboriginal dances were always in rings...'. Music and dance as a sign of identity in the Argentine Chaco". Yearbook for Traditional Music 41: 138-165. http://www.jstor.org/stable/pdf/25735482.pdf

Citro, Silvia, Mariana Gómez, Soledad Torres Agüero, Lucrecia Greco, Ema Cuañeri, Romualdo Diarte, Amanda García, Ramón González, Gerson Ortiz, Paula Ortiz, Alejandra Quiroga e Isabel Salomón. 2016. Memorias, músicas, danzas y juegos de los qom 
de Formosa. Buenos Aires: Universidad de Buenos Aires / Facultad de Filosofía y Letras. http://publicaciones.filo.uba.ar/memorias-m\%C3\%BAsicas-danzas-y-juegos-de-los-qom

Citro, Silvia, Yanina Mennelli y Soledad Torres Agüero. 2017. “'Cantando al patrimonio...’: las expresiones indígenas, entre discursos globales y creatividades locales”. Antípoda: Revista de Antropología y Arqueología 29: 175-197. https://dx.doi.org/10.7440/antipoda29.2017.08

Citro, Silvia y Soledad Torres Agüero. 2012. “'Es un ejemplo no solamente para los de su raza qom sino para toda la juventud formoseña'. El patrimonio cultural inmaterial y la controvertida política formoseña”. RUNA 33 (2): 157-174. https://dialnet.unirioja.es/servlet/ articulo?codigo $=4815766$

—. 2015. "Las músicas indígenas del Chaco argentino entre la hibridación y la exotización”. Le Journal de la Société des Américanistes 101: 101-116. https://journals.openedition.org/ jsa/14358

Crespo, Carolina, Flora Losada y Alicia Martín, comps. 2007. Patrimonio, políticas culturales y participación ciudadana. Buenos Aires: Antropofagia.

Cuatro mujeres: cantos de la tierra. 2005. Con el apoyo del Fondo Nacional de las Artes de Argentina y la Asociación Civil Runa Wasi. CD. https://soundcloud.com/ema-cua-eri/sets/ cuatro-mujeres-cantos-de-la-tierra

Domínguez, María Eugenia. 2007. "De negros a afro. Práticas culturais negras e elaboração de categorias étnico-raciais em Buenos Aires, Argentina”. Ilha 9 (1-2): 101-118. https://periodicos.ufsc.br/index.php/ilha/article/view/6297

Fernández Bravo, Nicolás. 2016. "El regreso del cabecita negra. Ruralidad, desplazamiento y reemergencia identitaria entre los santiagueños ‘afro'”. En Cartografías afrolatinoamericanas 2: perspectivas situadas en Argentina, editado por Lea Geler y Florencia Guzmán, 161-182. Buenos Aires: Biblos.

Frigerio, Alejandro. 2000. Cultura negra en el Cono Sur: representaciones en conflicto. Buenos Aires: Ediciones de la Universidad Católica Argentina.

—. 2006. “'Negros’ y ‘blancos’ en Buenos Aires: repensando nuestras categorías raciales”. Temas de Patrimonio Cultural 16: 77-98. http://www.elortiba.org/old/pdf/Frigerio_Negros_y_ blancos_Bs_As.pdf

Frigerio, Alejandro y Eva Lamborghini. 2011. “(De)mostrando cultura: estrategias políticas y culturales de visibilización y reivindicación en el movimiento afroargentino”. Boletín Americanista 63: 101-120. https://core.ac.uk/download/pdf/39088586.pdf

García Canclini, Néstor. 1999. "Los usos sociales del patrimonio cultural”. En El patrimonio cultural de México, compilado por Enrique Florescano, 57-85. Ciudad de México: Fondo de Cultura Económica.

Geler, Lea. 2016. "Categorías raciales en Buenos Aires. Negritud, blanquitud, afrodescendencia y mestizaje en la blanca ciudad capital”. Runa 37 (1): 71-87. https://doi.org/10.34096/ runa.v37i1.2226

Goldman, Marcio. 2014. “A relação afroindígena”. Cadernos de Campo 23 (23): 213-222. https://doi.org/10.11606/issn.2316-9133.v23i23p213-222 
Gonçalves, Jose Reginaldo Santos. 1996. A retórica da perda: os discursos do patrimônio cultural no Brasil. Río de Janeiro: UFRJ-IPHAN.

Gravano, Ariel. 1985. El silencio y la porfía. Buenos Aires: Corregidor.

Grosso, Juan Luis. 2008. Indios muertos, negros invisibles. Córdoba: Encuentro.

Grüner, Eduardo. 2002. El fin de las pequeñas historias: de los estudios culturales al retorno (imposible) de lo trágico. Buenos Aires: Norma.

Guzmán, Florencia. 2010. Los claroscuros del mestizaje: negros, indios y castas en la Catamarca colonial. Córdoba: Encuentro.

Iñigo Carrera, Valeria. 2011. "La producción de la ‘cultura aborigen’ en el Chaco argentino. De naturalezas, estigmas, exotismos y fetichismos”. Interseções: Revista de Estudos Interdisciplinares 3 (1): 7-25. https://www.e-publicacoes.uerj.br/index.php/intersecoes/article/ view/4602

Kropff, Laura. 2004. “Teatro mapuche: arte, ritual, identidad y política”. Ilha 2 (5): 115-134. https://doi.org/10.5007/\%25x

Lacarrieu, Mónica. 2000. "Construcción de imaginarios locales e identidades culturales en la mundialización”. Ponencia presentada en el Seminario Nuevos retos y Estrategias de las Políticas Culturales frente a la Globalización, Institut d'Estudis Catalans, Barcelona, 22-25 de noviembre.

Lamborghini, Eva. 2015. "Candombe afro-uruguayo en Buenos Aires: nuevas formas de sociabilidad, política y apropiación del espacio público”. Tesis doctoral en Antropología, Facultad de Filosofía y Letras, Universidad de Buenos Aires, Buenos Aires.

—. 2019. "Performances afro y movilización social: articulaciones entre arte, política y memoria en Buenos Aires”. Cuicuilco 26 (75): 225-248. http://www.scielo.org.mx/pdf/crca/ v26n75/0185-1659-cuicui-26-75-225.pdf

López, Laura. 2006. “De transnacionalización y censos. Los 'afrodescendientes’ en Argentina”. AIBR: Revista de Antropología Iberoamericana 1 (2): 265-286.

López, Mario. 2011. Una historia a contramano de la "oficial": Demetrio Acosta "el Negro Arigós” y la Sociedad Coral Carnavalesca Negros Santafesinos. Santa Fe: Cámara de Diputados de la Provincia de Santa Fe.

Maffia, Diana y Liliana Tamagno. 2011. "Lo afro y lo indígena en Argentina. Aportes desde la antropología social al análisis de las formas de la visibilidad en el nuevo milenio". Boletín Americanista 63: 121-141. https://revistes.ub.edu/index.php/BoletinAmericanista/ article/view/13571

Martínez Sarasola, Carlos. 1992. Nuestros paisanos los indios: vida, historia y destino de las comunidades indígenas en la Argentina. Buenos Aires: Emecé.

Ochoa Gautier, Ana María. 2003. Músicas locales en tiempos de globalización. Buenos Aires: Norma.

Parody, Viviana. 2015. "Patrimonio intangible, políticas culturales y universidades públicas en las acciones de 'salvaguardia' del candombe (afro) uruguayo en Buenos Aires”. En Actas Primer Encuentro de Patrimonio Vivo. Buenos Aires: Ministerio de Cultura de la Nación Argentina. 
Povinelli, Elizabeth A. 2002. The cunning of recognition: indigenous alterities and the making of Australian multiculturalism. Durham; Londres: Duke University Press.

Prats, Llorenç. 1997. Antropología y patrimonio. Barcelona: Ariel.

Ramos, Alcida. 1998. Indigenism: ethnic politics in Brazil. Madison: Wisconsin University Press.

Ratier, Hugo. 1971. El cabecita negra. Buenos Aires: Centro Editor de América Latina.

Reid Andrews, George. 1989. Los afroargentinos de Buenos Aires. Buenos Aires: Ediciones de La Flor.

Restrepo, Eduardo. 2007. “El 'giro al multiculturalismo' desde un encuadre afro-indígena”. Journal of Latin American and Caribbean Anthropology 12 (2): 475-486. 10.1525/jlaca.2007.12.2.475

Rivera Cusicanqui, Silvia. 2010. Ch’ixinakax utxiwa: una reflexión sobre prácticas y discursos descolonizadores. Buenos Aires: Retazos / Tinta Limón.

Rodríguez, Manuela. 2019. "Imaginarios, estéticas y performatividades negras en el Litoral: tensiones entre archivos y repertorios”. Ponencia presentada en el XXXIX Encuentro de Geohistoria Regional, Universidad del Nordeste e Instituto Superior de Formación Docente de Ituzaingó, Corrientes, 12-13 de septiembre.

Roig, Elizabeth. 1996. "El coro toba Chelaalapi: un bolsón aislado de música tradicional”. Revista Argentina de Musicología 1: 71-80. http://ojs.aamusicologia.org.ar/index.php/ram/ article/view/9/6

Rossi, Vicente. 1926. Cosas de negros: los orígenes del tango y otros aportes al folklore rioplatense. Rectificaciones históricas. Río de la Plata; Buenos Aires: Librería Hachette.

Rotman, Mónica. 2004. Antropología de la cultura y el patrimonio. Córdoba: Ferreira Editor.

Ruiz, Irma y Silvia Citro. 2002. “Toba”. En Diccionario Enciclopédico de la Música Española e Hispanoamericana, editado por Sociedad General de Autores, 308-315. Madrid: Editores de España.

Schávelzon, Daniel. 2003. Buenos Aires negra: arqueología histórica de una ciudad silenciada. Buenos Aires: Emecé Editores.

Schechner, Richard. 2000. Performance: teoría y práctica intercultural. Buenos Aires: Libros del Rojas.

Segato, Rita. 1999. "Identidades políticas/alteridades históricas: una crítica a las certezas del pluralismo global”. Anuario Antropológico 97: 161-196. https://doi.org/10.34096/runa. v23i1.1304

Solomianski, Alejandro. 2003. Identidades secretas: la negritud en Argentina. Buenos Aires: Ediciones Solar.

Spivak, Gayatri. 1987. In other worlds: essays in cultural politics. Nueva York: Methuen. 
Tangó de San Miguel: candombes del Litoral argentino. 2008. Idea original y producción de Pablo Suárez. Con el apoyo del Programa Identidad Entrerriana, Argentina. CD multimedia. https://www.youtube.com/watch?v=MInl6lAXUHE\&list=PLtDkaGAqALt4vwqp38r QRTMugc4uJfWl8\&index $=1 \& \mathrm{t}=386 \mathrm{~s}$

Taylor, Diana. 2003. The archive and the repertoire: performing cultural memory in the Americas. Durham: Duke University Press.

Terán, Oscar. 1987. Positivismo y nación en la Argentina. Buenos Aires: Puntosur.

Torres Agüero, Soledad, Juan Carlos Caballero, Romualdo Diarte y Clara Sarraute. 2007a. NamaqtaGa Ca César (Visitando a César). Argentina: Na la vill'llaGac qataq na lquii na qarhuo' (La Voz y la Imagen de Nuestra Gente) / Fondo Nacional de las Artes. Cortometraje, 11:30 min. https://vimeo.com/5232075

-.2007b. Potai Napokna (Colonia La Primavera). Argentina: Na la vill'llaGac qataq na lquii na qarhuo' (La Voz y la Imagen de Nuestra Gente) / Fondo Nacional de las Artes. Cortometraje, 19:29 min. https://vimeo.com/5232705

Turner, Victor. (1985) 2002. "La antropología de la performance”. En Antropología del ritual, 103-144. Ciudad de México: INAH/ENAH.

Unesco. 2012. Sitios de memoria y culturas vivas de los afrodescendientes en Argentina, Paraguay y Uruguay. Vol. 1, Huellas e identidades. Montevideo: Unesco. http://unesdoc.unesco. org/images/0022/002277/227700s.pdf

Vega, Carlos. 1944. Panorama de la música popular argentina en seis ensayos sobre la esencia del folklore. Buenos Aires: Losada.

—.1952. Las danzas populares argentinas. Buenos Aires: Ministerio de Educación de la Nación.

Victorica, Benjamín. 1885 Campaña del Chaco. Buenos Aires: Imprenta Europea.

Vivaldi, Ana. 2008. "Un indio tiene que pagar”: violencia y disputas en la construcción de subjetividades indígenas. Vancouver: Calacs.

Yúdice, George. 2002. El recurso de la cultura: usos de la cultura en la era global. Barcelona: Gedisa.

Zapata Gollán, Agustín. 1966. "El carnaval en Santa Fe (República Argentina)”. En Actas del XXXVI Congreso de Americanistas, vol. 2, 439-444. Sevilla: Congreso Internacional de Americanistas.

Žižek, Slavoj. 1998. "Multiculturalismo o la lógica cultural del capitalismo multinacional”. En Estudios culturales: reflexiones sobre el multiculturalismo, editado por Frederic Jameson y Slavoj Žižek, 137-188. Buenos Aires: Paidós. 